
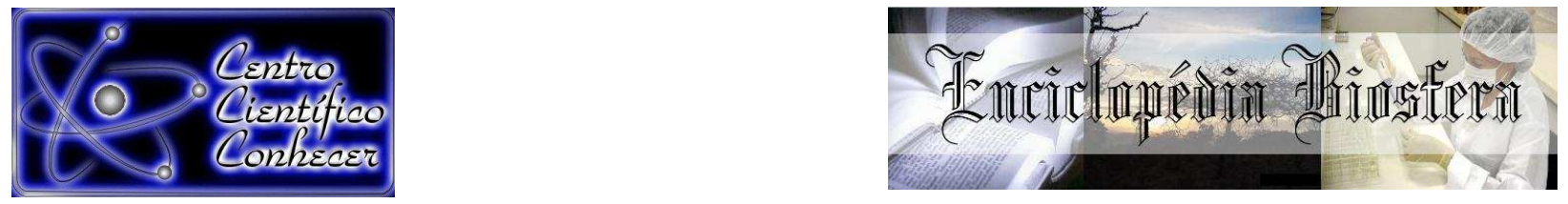

\title{
CONTRIBUIÇÃO TAXONÔMICA AO ESTUDO DO GÊNERO Senna MILL. (LEGUMINOSAE, CAESALPINIOIDEAE) NO ESTADO DE MATO GROSSO, BRASIL
}

\section{Sandra Dias Souza ${ }^{1}$, Aline Gonçalves Spletozer ${ }^{2}$, Lucirene Rodrigues ${ }^{3}$, Célia Regina Araújo Soares Lopes ${ }^{4}$, José Martins Fernandes ${ }^{5}$ \\ ${ }^{1}$ Graduada em Licenciatura Plena em Ciências Biológicas pela Universidade do Estado de Mato Grosso (UNEMAT), Campus de Alta Floresta \\ ${ }^{2}$ Graduanda em Engenharia Florestal pela UNEMAT, Campus de Alta Floresta \\ ${ }^{3}$ Professora Mestre da Faculdade de Ciências Biológicas e Agrárias, UNEMAT, Campus de Alta Floresta \\ ${ }^{4}$ Professora Doutora da Faculdade de Ciências Biológicas e Agrárias, UNEMAT, Campus de Alta Floresta \\ ${ }^{5}$ Professor Doutor da Faculdade de Ciências Biológicas e Agrárias, UNEMAT, Campus de Alta Floresta (ferbiobot@gmail.com)}

\section{Recebido em: 03/10/2016 - Aprovado em: 21/11/2016 - Publicado em: 05/12/2016} DOI: 10.18677/EnciBio 2016B 029

\section{RESUMO}

O gênero Senna Mill. possui distribuição Pantropical e está representado por 300 espécies, dentre elas, 80 no Brasil e 22 em Mato Grosso. O gênero é reconhecido principalmente pela presença de nectários entre os folíolos na maioria das espécies, anteras basifixas e poricidas, ausência de bractéolas e também pelos legumes deiscentes ou raramente indeiscentes. O objetivo foi apresentar uma contribuição taxonômica das espécies Senna bacillaris (L.f.) H.S.Irwin \& Barneby e S. cana (Nees \& Mart.) H.S. Irwin \& Barneby para a flora de Mato Grosso a partir do estudo taxonômico das novas ocorrências depositadas no Herbário da Amazônia Meridional (HERBAM). O trabalho foi realizado entre março e junho de 2016, a partir da análise morfológica das exsicatas de Senna depositadas no HERBAM. O HERBAM possui exsicatas de 15 espécies de Senna, todas coletadas em Mato Grosso, dentre elas, $S$. bacillaris e $S$. cana não citadas para o Estado no site Flora do Brasil. S. bacillaris foi coletada no município de Paranaíta. Todas as folhas tem nectários entre os pares de folíolos, estreitamente piriformes, folíolos 2 pares, $5,5-6,5 \times 3-4 \mathrm{~cm}$. $S$. cana foi coletada no município de Alta Floresta e possui nectários entre todos os pares de folíolos, cônicos, folíolos 4-8 pares, 4,2-6,9x1,8-2,2 cm. Os caracteres de $S$. bacillaris foram mais consistentes conforme a descrição da última revisão do gênero, enquanto que, $S$. cana, apresentou maior variação morfológica em relação aos nectários extraflorais. O trabalho reforça a ampliação de 22 para 24 espécies de Senna para a Flora de Mato Grosso.

PALAVRAS-CHAVE: Amazônia Matogrossense, Fabaceae, fedegoso.

TAXONOMIC CONTRIBUTION TO THE STUDY OF GENUS Senna MILL. (LEGUMINOSAE, CAESALPINIOIDEAE) IN MATO GROSSO STATE, BRAZIL

\footnotetext{
ABSTRACT

The genus Senna Mill. has Pantropical distribution and is represented by 300 species, among them, 80 in Brazil and 22 in Mato Grosso. Genus is mainly ENCICLOPÉDIA BIOSFERA, Centro Científico Conhecer - Goiânia, v.13 n.24; p.322 2016
} 
recognized by the presence of nectaries between the leaflets in most species, basifixas anthers and poricidal, absence of bracteoles and also by dehiscent or indehiscent rarely vegetables. The aim was to present a taxonomic contribution of species Senna bacillaris (L. F.) H.S.Irwin \& Barneby and Senna cana (Nees \& Mart.) H.S. Irwin \& Barneby for Mato Grosso flora from the taxonomic study of new records deposited in the Herbarium of the Southern Amazon (HERBAM). The study was conducted between March and June 2016, from the morphological analysis of herbarium specimens of Senna deposited in HERBAM. The HERBAM has specimens of 15 species of Senna, all collected in Mato Grosso, among them, $S$. bacillaris and $S$. cana not cited for the State on the site Flora of Brazil. $S$. bacillaris was collected in the municipality of Paranaíta. All leaves have nectaries between pairs of leaflets, narrowly pyriform, leaflets 2 pairs, $5,5-6,5 \times 3-4 \mathrm{~cm}$. $S$. cana was collected in the municipality of Alta Floresta and has nectaries between all pairs of leaflets, conical, leaflets 4-8 pairs, 4,2-6,9x1,8-2,2 cm. The $S$. bacillaris characters were more consistent as the description of the last revision of the genus, while $S$. cana, showed greater morphological variation in relation to nectaries. The work reinforces the expansion from 22 to 24 species of Senna for Flora of Mato Grosso.

KEYWORDS: Amazonia Matogrossense, Fabaceae, fedegoso.

\section{INTRODUÇÃO}

O Estado de Mato Grosso possui cerca de 903 mil $\mathrm{Km}^{2}$ e, dentre os naturalistas que registraram as paisagens e espécies da flora, estão Alexandre Rodrigues Ferreira, no século XVIII, considerado o primeiro expedicionário no Estado (LEITE \& LEITE, 2010), posteriormente, vários botânicos e naturalistas passaram pelo estado como Frederico Carlos Hoehne, no início do século XX, durante as expedições organizadas por Marechal Cândido da Silva Rondon. Desde as primeiras coletas até os tempos atuais, exsicatas da flora do Estado foram depositadas em coleções estrangeiras e brasileiras. No Estado de Mato Grosso são encontrados seis herbários cadastrados na Rede Brasileira de Herbários, dentre eles, o Herbário da Amazônia Meridional (HERBAM), localizado na Universidade do Estado de Mato Grosso, Campus Universitário de Alta Floresta.

O HERBAM foi registrado em 2007, possui atualmente cerca de $500 \mathrm{~m}^{2}$ e mais de 14.000 exsicatas depositadas, sendo considerada uma importante coleção botânica para o Norte do Estado (SOARES LOPES, 2015; GASPER, 2016), oferecendo dados para pesquisas de Graduação e Pós-graduação, bem como para atividades de Educação Ambiental com alunos do Ensino Básico da região de Alta Floresta. Segundo Soares Lopes (2015) as exsicatas da coleção são oriundas de diversas tipologias florestais, desde floresta ombrófila densa e aberta, floresta estacional semidecidual e decidual, Cerrado, campinaranas e campos rupestres da Amazônia, advindas de diversos projetos desenvolvidos pela equipe do herbário e instituições parceiras. Está situado em uma região estratégica do Mato Grosso e vem destacando-se na amostragem de vegetações inexploradas e/ou com poucas coletas da Floresta Amazônica desse Estado. Trabalhos recentes vêm apresentando constantemente novas ocorrências para a flora do Estado do Mato Grosso (FERNANDES et al., 2015).

O Estado possui cerca de 5.500 espécies de embriófitas, predominantemente de angiospermas, distribuídas nos domínios fitogeográficos do Cerrado, Pantanal e Floresta Amazônica (FLORA DO BRASIL, 2016). O Cerrado de Mato Grosso possui cerca de 4.160 espécies de embriófitas; a Floresta Amazônica está representada por 3.360 espécies, enquanto que, o Pantanal, com 800 espécies (FABACEAE, 2016). 
As embriófitas contemplam desde as briófitas até as angiospermas, sendo a família Leguminosae (Fabaceae) uma das principais em número de espécies (JUDD et al., 2009), tradicionalmente dividida nas subfamílias Caesalpinioideae, Mimosoideae e Papilionoideae. A família está representada por 727 gêneros e cerca de 19.325 espécies é considerada a terceira maior entre as angiospermas, com distribuição cosmopolita (LEWIS et al., 2005). Na flora brasileira é a principal família com 2.807 espécies e 222 gêneros, enquanto que, em Mato Grosso, está representada por 120 gêneros e 607 espécies (FABACEAE, 2016), números que podem aumentar com mais coleções botânicas e coletas no Estado.

Dentre os principais gêneros de Caesalpinioideae está Senna Mill., considerado pantropical com cerca de 300 espécies (LEWIS et al., 2005), destas, 80 no Brasil e 22 no Estado de Mato Grosso (SOUZA \& BORTOLUZZI, 2016). O gênero é reconhecido pela presença de nectários foliares entre os folíolos na maioria das espécies, ausência de bractéolas, filetes geralmente retos dos estames maiores e até duas vezes o comprimento das anteras, anteras basifixas e poricidas (IRWIN \& BARNEBY, 1982).

As espécies de Senna são de grande importância para as pessoas, principalmente como recursos medicinais, ornamentais e como alimento para pequenos animais silvestres (LORENZI, 2002, 2008, 2009; LORENZI \& MATOS, 2008). As espécies medicinais mais conhecidas do gênero são Senna alata (L.) Roxb., S. corymbosa (Lam.) H.S.Irwin \& Barneby, S. obtusifolia (L.) H.S.Irwin \& Barneby, S. occidentalis (L.) Link e S. spectabilis (DC.) H.S.Irwin \& Barneby (LORENZI \& MATOS, 2008). As espécies S. alata, S. hirsuta (L.) H.S.Irwin \& Barneby, S. obtusifolia, S. occidentalis e S. silvestres (Vell.) H.S.Irwin \& Barneby são consideradas as principais espécies daninhas no Brasil (LORENZI, 2000). As espécies do gênero citadas como plantas daninhas, são devido a grande quantidade de sementes produzidas e a resistência ao manejo em plantações e pastagens.

As espécies S. appendiculata (Vogel) Wiersema, S. polyphylla (Jacq.) H.S. Irwin \& Barneby e $S$. alata são as mais conhecidas como ornamentais (LORENZI \& SOUZA, 2008). No entanto, outras espécies também aparecem em estudos etnobotânicos como ornamentais, como $S$. pendula e $S$. macranthera na Floresta Atlântica (FERNANDES et al., 2014).

O objetivo do trabalho foi realizar o estudo taxonômico das novas ocorrências de Senna Mill. para a flora do Estado de Mato Grosso, realizando-se diagnoses morfológicas e apresentando comentários taxonômicos e informações sobre a distribuição geográfica das espécies.

\section{MATERIAL E MÉTODOS}

O trabalho foi realizado entre março e junho de 2016, a partir da análise morfológica das exsicatas do gênero Senna depositadas no HERBAM. O sistema de classificação foi baseado em LEWIS et al. (2005) e as novas ocorrências baseadas nos trabalhos de IRWIN \& BARNEBY (1982), FERNANDES et al. (2015) e SOUZA \& BORTOLUZZI (2016). As diagnoses morfológicas foram realizadas no Laboratório de Morfologia Vegetal do HERBAM. A terminologia empregada está disponível em FERNANDES \& GARCIA (2014).

\section{RESULTADOS E DISCUSSÃO}

Senna Mill., Gard. Dict. Abr. (ed. 4) 3: Senna. 1754.

Árvores, arbustos ou subarbustos. Folhas paripinadas; estípulas presentes, persistentes ou caducas, estipelas ausentes; nectário foliar presente no pecíolo ou 
entre os pares de folíolos, às vezes ausentes; folíolos opostos, raramente subopostos; venação peninérvea. Inflorescências racemosas ou paniculadas, multifloras até bifloras, axilares ou terminais; brácteas presentes e bractéolas ausentes; flores pentâmeras, zigomorfas ou levemente assimétricas; hipanto quase inexistente; cálice dialissépalo, esverdeado ou amarelado; corola dialipétala, amarela; androceu dialistêmones, 7 estames férteis, heterodínamos, 3 maiores adaxiais, 4 menores medianos, 3 estaminódios abaxiais; ovário pluriovulado. Fruto legume bacóide, deiscente, raramente indeiscente; sementes compressas, geralmente areoladas.

Comentários: A coleção do Herbário da Amazônia Meridional possui exsicatas de 15 espécies do gênero Senna. As espécies depositadas no herbário com ocorrência citada para o Estado de Mato Grosso são S. alata (L.) Roxb., S. chrysocarpa (Desv.) H.S.Irwin \& Barneby, S. pendula (Humb.\&Bonpl. ex Willd.) H.S.Irwin \& Barneby, S. georgica H.S.Irwin \& Barneby, S. latifolia (G.Mey.) H.S.Irwin \& Barneby, S. multijuga (Rich.) H.S.Irwin \& Barneby, S. obtusifolia (L.) H.S.Irwin \& Barneby, S. occidentalis (L.) Link, S. pilifera (Vogel) H.S.Irwin \& Barneby, S. quinquangulata (Rich.) H.S.Irwin \& Barneby, S. silvestris (Vell.) H.S.Irwin \& Barneby, S. spinescens (Hoffmanns.ex Vogel) H.S.Irwin \& Barneby e S. tapajozensis (Ducke) H.S.Irwin \& Barneby.

As espécies S. bacillaris (L.f.) H.S.Irwin \& Barneby e S. cana (Nees \& Mart.) H.S. Irwin \& Barneby são novas ocorrências para Mato Grosso e depositadas no HERBAM conforme mencionado por FERNANDES et al. (2015) e ilustradas na Figura 1. Foram coletadas no Norte do estado, a partir da intensificação de expedições científicas na região, a partir de trabalhos de conclusão de curso e nos programas de resgate de flora para coleção científica da Usina Hidrelétrica Teles Pires.

Senna bacillaris (L.f.) H.S. Irwin \& Barneby, Mem. New York Bot. Gard. 35: 111. 1982.

(Figura 1)

Arbustos. Ramos jovens esparso-tomentosos. Estípulas $3-4 \times 0,7-0,8 \mathrm{~mm}$, lanceoladas, pubescentes; pecíolos 3-3,8 cm compr., esparsamente tomentosos; raque 1,5-2 cm compr.; nectários entre todos os pares de folíolos, estreitamente piriformes; folíolos 2 pares, 5,5-6,5 x 3-4 cm, ovados, ápice acuminado, base oblíqua, face abaxial esparsamente serícea, face adaxial glabra, nervura principal submarginal, margem inteira. Inflorescência racemosa terminal. Flores assimétricas; cálice 0,5-0,7 x 0,3-0,4 cm, puberulento externamente; corola 0,9-1,5 x 0,7 cm; estames adaxiais 3, filetes 1-4,7 mm compr., anteras 5-7 mm compr., estames medianos 4, filetes 1-4 mm compr., anteras 5-7 mm compr., estaminódios abaxiais 3; ovário 1,8-2,1 cm compr., curvo, densamente tomentoso; estilete 0,4-0,5 cm compr., dilatado, curvo esparsamente tomentoso. Fruto não observado. 


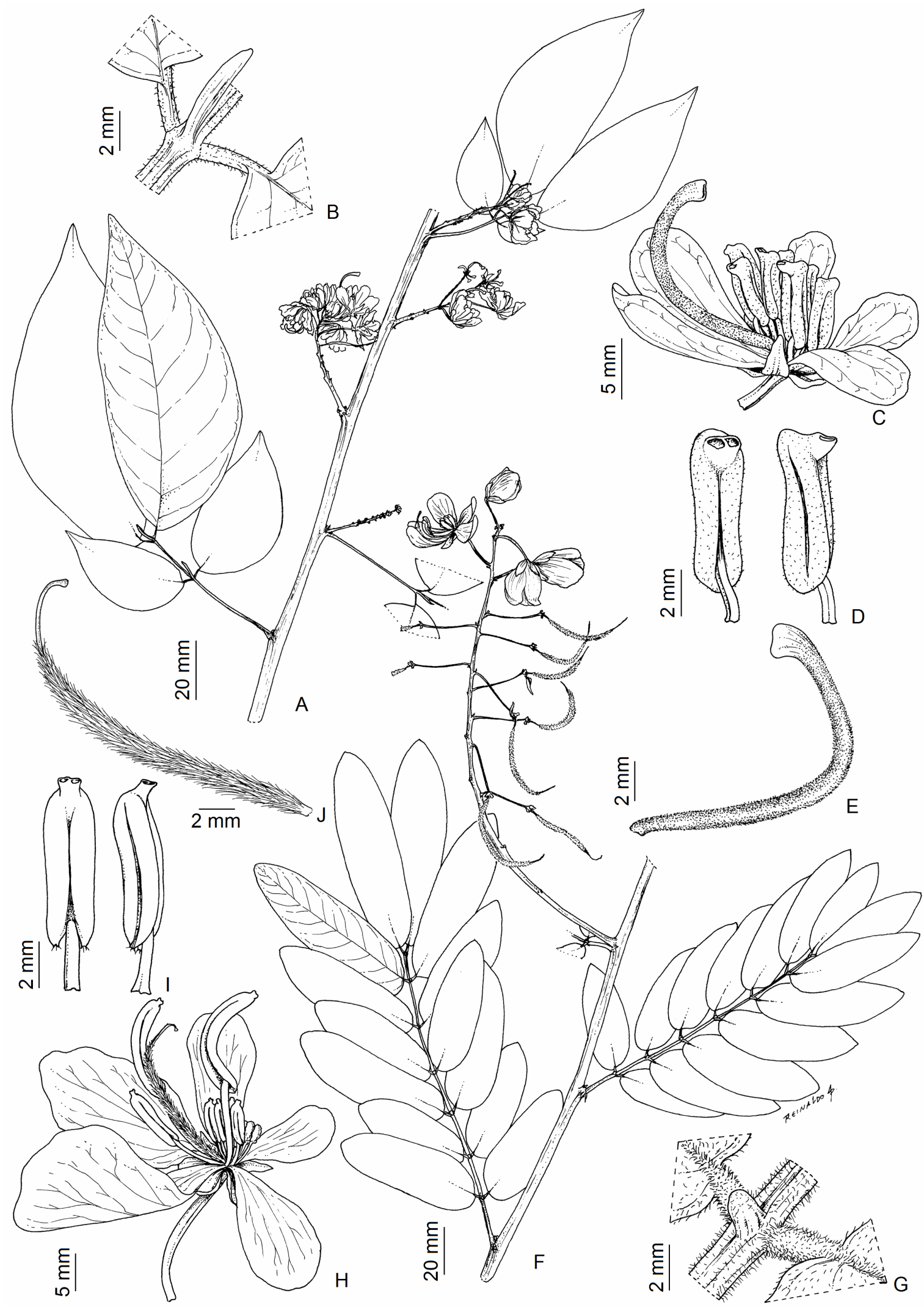

FIGURA 1. llustração de duas novas ocorrências do gênero Senna para Mato Grosso. Senna bacillaris: A, parte do ramo com uma folha e inflorescência; B, nectário extrafloral; C, flor; D, Estame; E, Gineceu. Senna cana: $F$, parte do ramo com uma folha; $G$, nectário extrafloral; $H$, flor; I, Estame; J, Gineceu. llustração: Reinaldo Pinto. 
Comentários: os caracteres que definem $S$. bacillaris consistem em folíolos com venação reticulada e margens planas, base dos folíolos fortemente oblíqua, inflorescência paniculada com eixo primário flexuoso, sépalas e pétalas relativamente grandes, fruto com muitas sementes e amplamente marginado ao longo das suturas e sementes em duas séries (IRWIN \& BARNEBY, 1982). Segundo os mesmos autores, as várias espécies estreitamente relacionadas com S. bacillaris diferem em uma ou várias dessas características; dentre as espécies mais relacionadas estão S. fruticosa (Mill.) H.S. Irwin \& Barneby, S. papillosa (Britton \& Rose) H.S. Irwin \& Barneby e S. hayesiana (Britton \& Rose) H.S. Irwin \& Barneby, porém, na América Central, mas diferem por apresentar margens dos folíolos revolutos.

Na América Central a espécie ocorre na Costa Rica, Nicarágua e Panamá; na América do Sul ocorre no Brasil, Colômbia, Equador, Guiana, Peru, Suriname e Venezuela (ILDIS, 2016). No Brasil tem registros de ocorrência nos Estados do Amazonas, Bahia, Maranhão, Minas Gerais, Pará, Pernambuco, Roraima e Sergipe, nos domínios fitogeográficos da Amazônia e Mata Atlântica (SOUZA \& BORTOLUZZI, 2016). No Estado de Mato Grosso foi coletada em floresta de terra firme, sob domínio da Amazônia, no município de Paranaíta (Figura 2).

Material examinado: BRASIL. MATO GROSSO. Paranaíta, 12/IV/2012, fl. C.R.A. Soares-Lopes, M.; Barros, F.F.; Gazine, E.; Benetti e V.A. Moura 5984 (HERBAM).

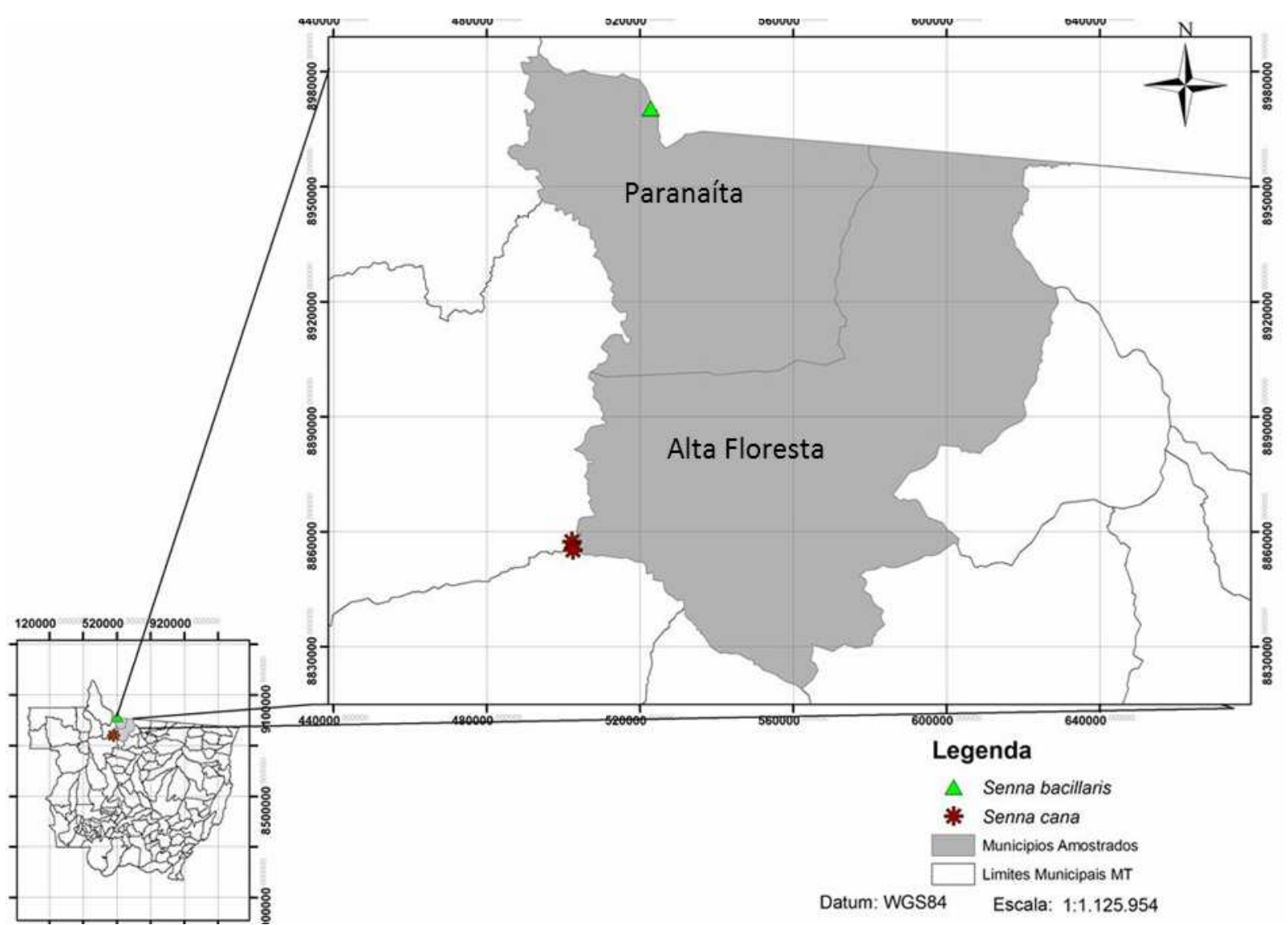

FIGURA 2. Pontos de distribuição geográfica das espécies Senna bacillaris e Senna cana (Leguminosae, Caesalpinioideae) no Estado de Mato Grosso. 
Senna cana (Nees \& Mart.) H.S. Irwin \& Barneby, Mem. New York Bot. Gard., 35: 226. 1982.

(Figura 1)

Árvores ou arbustos. Ramos jovens velutinos. Estípulas $2-7 \times 0,3 \mathrm{~mm}$, esparsamente velutinas; pecíolos 1,4-1,8 cm compr., velutinos, raque $7-12,5 \mathrm{~cm}$ compr.; nectários entre todos os pares de folíolos, cônicos; folíolos 4-8 pares, 4,2-6,9 x 1,8-2,2 cm, elípticos, ápice agudo, raramente obtuso; base oblíqua, face adaxial esparso velutino, abaxial velutina, tricomas glandulares presentes, nervura principal central. Inflorescência racemosa terminal. Flores zigomorfas; cálice 0,7-3,5 x 04-2,3 $\mathrm{cm}$, corola 1,4-2,4 x 0,9-1,4 cm; estames maiores 3, filetes 3-8,4 mm compr., anteras 9-13 mm compr., estames menores 4 , filetes $0,9-3 \mathrm{~mm}$ compr., anteras $4-7 \mathrm{~mm}$ compr., estaminódios adaxiais 3; ovário $1,3-1.9 \mathrm{~cm}$ compr., curvo, densamente viloso, estilete 3-5 mm compr., glabro, terminal, truncado. Fruto não observado.

Comentários: S. cana é uma espécie bastante polimórfica vegetativamente e assemelha-se a S. velutina (Vogel) H.S.Irwin \& Barneby na forma e duração das estípulas nos ramos, tipo de indumento dos folíolos e no tamanho da flor, mas diferencia-se por apresentar folíolos mais curtos e estreitos, geralmente na ausência do nectário extrafloral entre o primeiro par de folíolos, além de indícios escassos de que as valvas dos frutos são mais estreitas e com a presença de uma ala evidente no fruto, enquanto que $S$. velutina possui valvas mais largas e sem alas (IRWIN \& BARNEBY, 1982).

Segundo os mesmos autores, S. cana também diferencia das demais espécies da Série Laxiflorae (Bentham) Irwin \& Barneby por apresentar folhas entre 3 e 8 pares de folíolos, onde os folíolos do par distal não ultrapassam $6,5 \mathrm{~cm}$ de comprimento e corola entre 1,6-2,6 cm de comprimento, enquanto que as outras espécies possuem entre 2 e 6 pares de folíolos, folíolos do par distal chegando até $11 \mathrm{~cm}$ de comprimento e corola entre 2,5-3,5 cm de comprimento.

Para a flora de Goiás, área de Cerrado, a espécie é reconhecida por apresentar folíolos conspicuamente discolores de margem revoluta e com nectários extraflorais no terceiro e quatro pares de folíolos, associados às estípulas com base dilatadas e frutos cortados lateralmente (SANTOS, 2013).

No material coletado em Alta Floresta, Mato Grosso, sob domínio da Amazônia, todas as folhas apresentam nectários extraflorais. No Brasil ocorre nos Estados de Alagoas, Bahia, Espírito Santo, Goiás, Maranhão, Minas Gerais, Pará, Paraíba, Pernambuco, Piauí, Rio de Janeiro, São Paulo, Sergipe, além do Distrito Federal, nos domínios fitogeográficos da Amazônia, Caatinga, Cerrado e Mata Atlântica (SOUZA \& BORTOLUZZI, 2016). Em Mato Grosso foi coletada no município de Alta Floresta (Figura 2), porém, necessita-se de mais coletas na região para conhecer melhor a sua distribuição no estado.

Material examinado: BRASIL. MATO GROSSO. Alta Floresta, Eixo do circuito hidráulico da UHE salto Apiacás, margem direita, 15/V/2014, fl., C.R.A SoaresLopes, L.C Benevides, M.R.O; Freire e D.G. Macedo 7386 ( HERBAM).

\section{CONCLUSÃO}

O presente trabalho realizou o estudo taxonômico de duas novas ocorrências de Senna para flora do Mato Grosso, além de conhecer a riqueza do gênero para o estado, ampliando de 22 para 24 espécies para o Estado. Os caracteres de Senna bacillaris foram mais consistentes conforme a descrição da última revisão do gênero, enquanto que, Sena cana, apresentou maior variação morfológica em relação aos nectários extraflorais. 


\section{REFERÊNCIAS}

FABACEAE in Flora do Brasil 2020 em construção. Jardim Botânico do Rio de Janeiro. Disponível em: <http://floradobrasil.jbrj.gov.br/reflora/floradobrasil/FB115>. Acesso em: 25 Jun. 2016.

FERNANDES, J. M.; GARCIA, F. C. P.; AMOROZO, M. C. M.; SIQUEIRA, L. C.; MAROTTA, C. P. B.; CARDOSO, I. M. Etnobotânica de Leguminosae entre agricultores agroecológicos na Floresta Atlântica, Araponga, Minas Gerais, Brasil. Rodriguésia, v. 65, n. 2, p. 539-554, 2014.

FERNANDES, J. M.; SOARES-LOPES, C. R. A.; RIBEIRO, R. S.; SILVA, D. R. Leguminosae no acervo do Herbário da Amazônia Meridional, Alta Floresta, Mato Grosso. Enciclopédia Biosfera, v. 11, n. 21, p. 2272-2293, 2015.

FERNANDES, J. M; GARCIA, F. C. P. Expanding the description of Bionia bella Mart. ex Benth. (Leguminosae, Papilionoideae). Acta Botanica Brasilica, v. 28, n. 2, p. 141-146, 2014.

FLORA do Brasil 2020 em construção. Jardim Botânico do Rio de Janeiro. Disponível em: < http://floradobrasil.jbrj.gov.br/ >. Acesso em: 29 Set. 2016.

GASPER, A. L.; VIEIRA, A. O. S.; SOARES LOPES, C. R. A.; BIGIO, N.; MACEDO, G. E. L. Rede Brasileira de Herbários. Disponível em: http://www.botanica.org.br/rbh. Acessado em: 29 de setembro de 2016.

IBGE. Cidades. Disponível em: http://www.ibge.gov.br/cidadesat/topwindow.htm?. Acessado em maio de 2016.

ILDIS. International Legume Database \& Information Service. Disponível em http://www.ildis.org/. Acesso em: 20 de junho de 2016.

IRWIN, H. S.; BARNEBY, R. C. The American Cassinae, a synoptical revision o Leguminosae, Tribe Cassieae, subtribe Cassinae in the New World. Memoires of the New York Botanical Garden, v. 35, n. 1-2, p. 1-918, 1982.

JUDD, W. S.; CAMPBELL, C. S.; KELLOGG, E. A.; STEVENS, P. F.; DONOGHUE, M. J. Sistemática vegetal: um enfoque filogenético. 3 ed. Porto Alegre: Artmed. 632p., 2009.

LEITE, J. N.; LEITE, C. S. G. Alexandre Rodrigues Ferreira e a formação do pensamento social na Amazônia. Estudos avançados, v. 24, n. 68, p. 273-289, 2010.

LEWIS, G. P.; SCHRIRE, B.; MACKINDER, B.; LOCK, M. Legumes of the world. Kew: Royal Botanic Gardens, 577p., 2005.

LORENZI, H. Plantas daninhas do Brasil: terrestres, aquáticas, parasitas e tóxicas. 3 ed. Nova Odessa, São Paulo: Instituto Plantarum, 608p., 2000. 
LORENZI, H. Árvores brasileiras: Manual de identificação e cultivo de plantas do Brasil. 4 ed. Nova Odessa, São Paulo: Instituto Plantarum, 368p., 2002.

LORENZI, H. Plantas daninhas do Brasil: Plantas terrestres aquáticas parasitas e tóxica. 4 ed. Nova Odessa, São Paulo: Instituto Plantarum, 640p., 2008.

LORENZI, H. Árvores brasileiras: manual de identificação e cultivo de plantas do Brasil. Nova Odessa, São Paulo: Instituto Plantarum, 384p., 2009.

LORENZI, H.; MATOS, F. J. A. Plantas medicinais no Brasil nativas e exóticas. 2 ed. Nova Odessa, São Paulo: Instituto Plantarum, 544p., 2008.

LORENZI, H.; SOUZA, H. M. Plantas ornamentais no Brasil: arbustivas, herbáceas e trepadeiras. 4 ed. Nova Odessa, SP: Instituto Plantarum, 1088p., 2008.

MT. Geografia. Disponível em: http://www.mt.gov.br/geografia. Acessado em 15 de janeiro de 2016.

SANTOS, J. P. O gênero Senna Mill. (Leguminosae, Caesalpinioideae, Cassieae) na região Centro-oeste do Brasil, com ênfase nas espécies ocorrentes no Estado de Goiás. Dissertação de Mestrado. Universidade Federal de Goiás, 2013.

SOARES LOPES, C. R. A. Herbário da Amazônia Meridional. Unisanta Bioscience, v. 4 , n. 6, p. 36-39, 2015.

SOUZA, V. C.; BORTOLUZZI, R. L. C. Senna in Lista de Espécies da Flora do Brasil. Jardim Botânico do Rio de Janeiro. Disponível em: $<$ http://floradobrasil.jbrj.gov.br/jabot/floradobrasil/FB23149>. Acesso em:18 Jan. 2016. 